\title{
Antimicrobial peptide gene BdPho responds to peptidoglycan infection and mating stimulation in oriental fruit fly, Bactrocera dorsalis (Hendel)
}

\author{
Shi-Huo Liu' ${ }^{1,2}$, Hong-Fei Li ${ }^{1}$, Yang Yang ${ }^{1}$, Dong Wei ${ }^{1,2}$, Hong-Bo Jiang ${ }^{1,2}$, Wei Dou ${ }^{1,2}$, Guo-Rui Yuan ${ }^{1}$
} and Jin-Jun Wang ${ }^{1,2^{*}}$ (D)

\begin{abstract}
Phormicins belong to defensin family, which are important antimicrobial peptides (AMPs) in insects. These AMPs are inducible upon challenging by immune triggers. In the present study, we identified the cDNA of a phormicin gene (BdPho) in the oriental fruit fly, Bactrocera dorsalis (Hendel), a ruinous agricultural pest causing great economic losses to fruits and vegetables. The cDNA of BdPho contains a 282 bp open reading frame encoding 93 amino acid residues, and the predicted molecular weight and isoelectric point of BdPho peptide were $9.83 \mathrm{kDa}$ and 7.54 , respectively. Quantitative real-time PCR analyses showed that the transcription level of BdPho was the highest in adult during different developmental stages and was the highest in abdomen among adult tagmata. Moreover, BdPho was highly expressed in fat body among different tissues, both in female and male adult. The mRNA level of BdPho was significantly up-regulated to 7.46- and 14.53-fold at 3 and $6 \mathrm{~h}$ after the insects were challenged with peptidoglycans from Escherichia coli (PGN-EB), respectively, suggesting its antimicrobial activity against Gram-negative microorganisms. Furthermore, the expression level of BdPho was significantly up-regulated to 3.83-fold after mating, suggesting that female adults might enhance their immunity by up-regulating the expression level of $B d P h o$ during mating. These results firstly describe the basic properties of the phormicin gene from B. dorsalis, and lay the foundation for investigating functional properties of AMPs and exploring the molecular mechanisms in the immune system.
\end{abstract}

Keywords: Bactrocera dorsalis, Antimicrobial peptide, Phormicin, Immunity, Mating

\section{Introduction}

The natural immune system of insect consists of cellular and humoral responses. The cell-mediated immunity includes phagocytosis, pinocytosis, nodulation, and encapsulation of invading microbes (Schmidt et al. 2001). In contrast, the humoral response includes melanization and the secretion of antimicrobial peptides (AMPs). AMPs are one of the most essential molecules of the humoral immune response and are synthesized mainly in insect fat body (Hoffmann 1995; Hultmark 1993). During

\footnotetext{
*Correspondence: wangjinjun@swu.edu.cn

${ }^{1}$ Key Laboratory of Entomology and Pest Control Engineering, College of Plant Protection, Southwest University, Chongqing 400716, China Full list of author information is available at the end of the article
}

the past decades, AMPs have been the focus of intense research on insect immunity and are now regarded as a vital part of the defense system in insects. Insect AMPs are not only involved in the defense against invading microorganisms in the haemolymph, but also regulate the bacterial community homeostasis in host gut (Buchon et al. 2013). It has been reported that the categories and expression levels of AMP genes could affect bacterial resistance of host in Drosophila (Unckless et al. 2016) and gut symbiont which could in turn enhance insecticide resistance in Bactrocera dorsalis (Cheng et al. 2017). These interesting results broadened our knowledge in pest control and showed that insect AMPs could serve as target or gut-symbiont-killer to control pest indirectly. 
Defensins are the largest family of AMPs and are found in almost all organisms including animals, plants and microorganisms. The cysteine-rich polypeptide defensin was first isolated from the flesh fly, Sarcophaga peregrine (Matsuyama and Natori 1988). Thereafter, more and more different defensins have been identified from various insects. Insect defensins are widely investigated in the orders of Diptera, Coleoptera, Lepidoptera, Hemiptera, and Hymenoptera (Liu et al. 2017; Tian et al. 2010; Ueda et al. 2005; Wang et al. 2013b; Wen et al. 2009). Note worthily, defensin is also present in the ancient order of Odonata (Bulet et al. 1992), suggesting that insect defensins may derive from a common ancestor gene. Phormicin (also called phormia defensin) is a cysteine-rich antimicrobial peptide belonging to the defensin family. It was firstly identified in Phormia terraenovae (Lambert et al. 1989). Phormicins have broad-spectrum antimicrobial activity against both Gram-positive and Gram-negative bacteria, as well as fungi (Lambert et al. 1989; Lamberty et al. 1999, 2001).

The oriental fruit fly, B. dorsalis (Hendel) belonging to Tephritidae of Diptera, is one of the most destructive agricultural pests in many regions of the world (Clarke et al. 2005). Dipteran insects are considered as microorganism-rich and expected to be abundant in AMPs. To date, only five groups of AMPs have been identified in this species, including cecropins, defensins, attacins, bactrocerin, and diptericins (Dang et al. 2009; Jiang et al. 2014; Liao et al. 2015; Liu et al. 2017). To better understand the adaptation of $B$. dorsalis to different environments and also provide more natural molecules with potential for designing effective antibiotics applied in medicine and agriculture (Yi et al. 2014), it is worthy to identify more AMPs and analyze the immune response challenged by the immune triggers in $B$. dorsalis. Therefore, we initiated this study to identify a phormicinencoding gene $(B d P h o)$ in $B$. dorsalis, and to investigate the response model of $B d P h o$ to immune-stimulation. The results of this study provided fundamental information for understanding the molecular mechanisms in immune system of Tephritidae insects, and also provide innovative ideas for developing effective insecticides.

\section{Materials and methods}

\section{Insects}

The oriental fruit fly, B. dorsalis was originally obtained from Hainan province of China in 2008, and maintained under laboratory conditions at $27.5 \pm 0.5{ }^{\circ} \mathrm{C}, 75 \pm 5 \%$ relative humidity (RH), and a photoperiod of 14:10 (L:D). Larvae and adults were reared on artificial diets as previously described (Wang et al. 2013a). To obtain virgin adults, newly enclosed adults were sex-biased separated and reared in different cages until collection.
For the spatiotemporal expression profiles of BdPho, samples at different developmental stages and different tissues of adult were collected as described previously (Liu et al. 2017).

\section{RNA isolation and CDNA synthesis}

Total RNA of each sample was isolated separately using TRIZOL reagent (Invitrogen, Carlsbad, CA) according to the manufacturer instructions. Before cDNA synthesis, the contaminating genomic DNA of each RNA sample was digested with DNase I (Promega, Madison, WI). First-strand cDNA was synthesized as described previously (Liu et al. 2017).

\section{Molecular cloning}

The specific primers used for amplifying open reading frame of BdPho (forward, 5'-TTTCACACACCTCAGTA

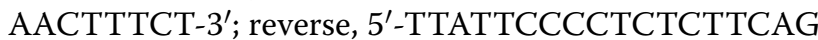
TCGT-3') were synthesized by Invitrogen in Shanghai, China. All PCRs were performed with $25 \mu \mathrm{L}$ reaction mixtures as described previously (Liu et al. 2017). PCR parameters were: $94{ }^{\circ} \mathrm{C}$ for $3 \mathrm{~min}$, followed by 35 cycles of $94{ }^{\circ} \mathrm{C}$ for $30 \mathrm{~s}$, anneal of $58{ }^{\circ} \mathrm{C}$ for $30 \mathrm{~s}$, and extension of $72{ }^{\circ} \mathrm{C}$ for $1 \mathrm{~min}$, final extension of $72{ }^{\circ} \mathrm{C}$ for $7 \mathrm{~min}$. The purified PCR products were sequenced by Invitrogen.

\section{Sequence analysis and phylogenetic tree construction}

Multiple sequence alignments were conducted using online software ClustalW2 (http://www.ebi.ac.uk/ Tools/msa/clustalw2). The theoretical parameters of the deduced protein sequences were computed using the ExPASy Proteomics Server (http://cn.expasy.org/tools/ pi_tool.html). The signal peptide and $\alpha$-helix structures of the BdPho were predicted by the SignalP 4.1 server program (http://www.cbs.dtu.dk/services/SignalP) (Petersen et al. 2011) and SOPMA secondary structure prediction (https://npsa-prabi.ibcp.fr/cgi-bin/npsa_automat.pl?page=/NPSA/npsa_sopma.html) (Combet et al. 2000), respectively. The online software DISULFIND (http://disulfind.dsi.unifi.it/) was used to predict cysteine disulfide bonding state and connectivity of the putative protein. And the tertiary structure of BdPho was predicted by online software SWISS-MODEL (https://swissmodel.expasy.org/) (Biasini et al. 2014).

The phylogenetic analysis on the basis of amino acid sequences was performed with MEGA 6.0 (Tamura et al. 2011) using the Maximum Likelihood (ML) method with 1000 bootstrap tests. The 15 amino acid sequences of phormicins for phylogenetic analysis were from Rhodnius prolixus, Panstrongylus megistus, Triatoma infestans, $T$. sordida, Apis cerana japonica, A. dorsata, A. cerana cerana, A. mellifera, B. dorsalis, B. oleae, Ceratitis capitata, Protophormia terraenovae, Sarcophaga peregrina, Aedes aegypti, 
and Musca domestica. All sequences were obtained from NCBI database (http://www.ncbi.nlm.nih.gov).

\section{Quantitative real-time PCR}

Quantitative real-time PCR (qRT-PCR) assay was carried out to investigate the relative mRNA levels of $B d P h o$ during various developmental stages, body parts, tissues, and female adults treated by immune triggers, as well as virgin females and mated females. The qRT-PCR was performed using GoTaq qPCR Master Mix (Promega) on a Mx3000P thermal cycler (Stratagene, La Jolla, CA). The $\alpha$-tubulin (GenBank accession number: GU269902) and RPS3 (XM_011212815) of B. dorsalis were served as internal reference genes based on our previous study (Shen et al. 2012) and RPS3 was also further validated in this study (Additional file 1: Figure S1, Additional file 2: Figure S2). All qRT-PCRs were performed in a final reaction mixture of $10 \mu \mathrm{L}$ contained $5 \mu \mathrm{L}$ qPCR Master Mix, $0.5 \mathrm{mM}$ each of forward and reverse primers, and $0.5 \mu \mathrm{L}$ cDNA templates (about $600 \mathrm{ng} / \mu \mathrm{L}$ ). The PCR parameters were $95{ }^{\circ} \mathrm{C}$ for $2 \mathrm{~min}$, followed by 40 cycles at $95^{\circ} \mathrm{C}$ for $15 \mathrm{~s}$ and $60{ }^{\circ} \mathrm{C}$ for $30 \mathrm{~s}$. To verify a single PCR product, the melting curve analysis from 60 to $95{ }^{\circ} \mathrm{C}$ after the cycling protocol was conducted. Each qRT-PCR experiment contained 3-4 independent biological replicates and 2 technical replicates. The qRT-PCR primers for BdPho (forward, 5'-TACTTTTCGCCGGTCCCAT-3'; reverse, 5'-CCACGTCCATTGCAGTAACC-3') and for the internal reference genes $\alpha$-tubulin (forward, 5'-CGCATTCATGGTTGATAACG-3'; reverse, $5^{\prime}$-GGGCACCAAGTTAGTCTGGA-3') and RPS3 (forward, 5'-TGGATCACCAGAGTGGATCA-3'; reverse, $5^{\prime}$-TAAGTTGACCGGAGGTTTGG-3') were designed using online software Primer 3 (http://primer3.ut.ee/) and synthesized by Invitrogen.

\section{Immune challenge}

The purified peptidoglycan from the Gram-positive bacterium Staphylococcus aureus (PGN-SA, InvivoGen, San Diego, CA) and Gram-negative bacterium E. coli O111:B4 (PGN-EB, InvivoGen) were used as immune triggers. PGN-EB and PGN-SA powder were diluted with the sterilized endotoxin-free water (InvivoGen) to a final concentration of $100 \mu \mathrm{g} / \mathrm{mL}$, respectively. Eighty 5-dayold virgin female adult flies were randomly collected and divided into four groups: named PGN-EB group, PGN-SA group, control group, and blank group, respectively. Each adult of PGN-EB group, PGN-SA group, and control group were injected with $200 \mathrm{~nL}$ PGN-EB solution, PGN-SA solution, and the sterilized endotoxin-free water, respectively, and no injection for adults in blank group. Three individuals of flies were randomly collected from each group after 3, 6 and 9 h post injection, respectively. Experiments were repeated three times independently and total RNA of each sample was extracted as described above.

\section{Mating experiment}

Female and male adults were sex-biased reared for 9 days after eclosion, respectively. On the 10th day, 20 individuals of each female and male flies randomly collected from corresponding cage and matched in a new cage to allow mating at dark. When female and male flies begin mating, the couples were carefully transferred to small cages and raised for $12 \mathrm{~h}$, avoiding disturbing. Finally, six individuals of each mated and virgin female flies were randomly collected. Total RNA isolation was performed as described above. The experiment was repeated three times independently.

\section{Data analysis}

The relative expression levels were calculated based on the expression level of reference genes by qBase (Hellemans et al. 2007) and data were analyzed with SPSS 19.0 software (IBM, Chicago, IL). Significant differences were analyzed with $t$-test and one-way ANOVA (followed by a Tukey test) for comparison of two means or multiple comparisons, respectively.

\section{Results \\ Sequence and phylogenetic analysis of BdPho}

The cDNA fragment of BdPho (GenBank accession no. KY038166) was amplified by PCR (Fig. 1a). The 365 bp cDNA sequence has an ORF of 282 nucleotides encoding a protein of 93 amino acid residues. The predicted molecular mass and isoelectric point of BdPho peptide were $9.83 \mathrm{kDa}$ and 7.54 , respectively. The predicted tertiary structure showed that BdPho contained a conserved " $\alpha \beta \beta$ " structure (Fig. 1b) that is widely distributed in insect defensin family. The first 22 amino acids at the $\mathrm{N}$-terminus of BdPho were predicted as a signal peptide (Fig. 2), suggesting that phormicin in B. dorsalis is a secretory peptide. Two $\alpha$-helix regions and three cysteine disulfide bonds were found at the mature peptide region of BdPho (Fig. 2).

The phylogenetic analysis showed that phormicins in dipteran, hemipteran, and hymenopteran species were separated into three corresponding clades (Fig. 3). The BdPho was closely related to the phormicin of olive fruit fly (B. oleae) with a bootstrap value of $96 \%$.

\section{Spatiotemporal expression profiles of $B d P h o$}

The results of developmental expression profiles of $B d P h o$ showed that the highest and lowest mRNA levels 
a

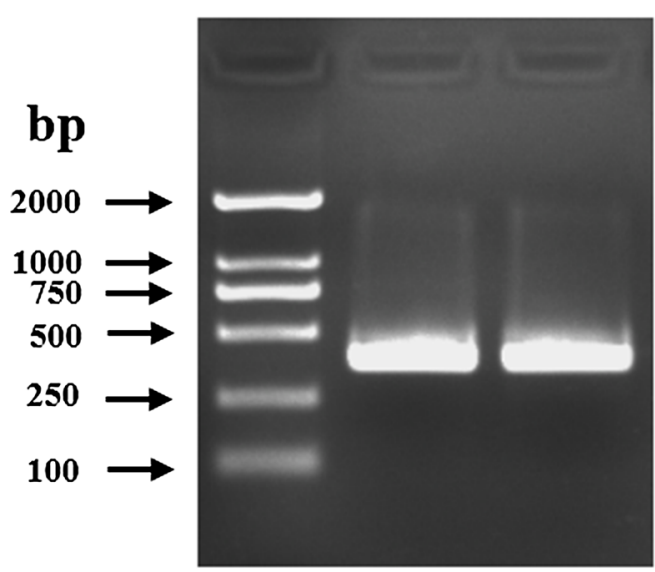

b

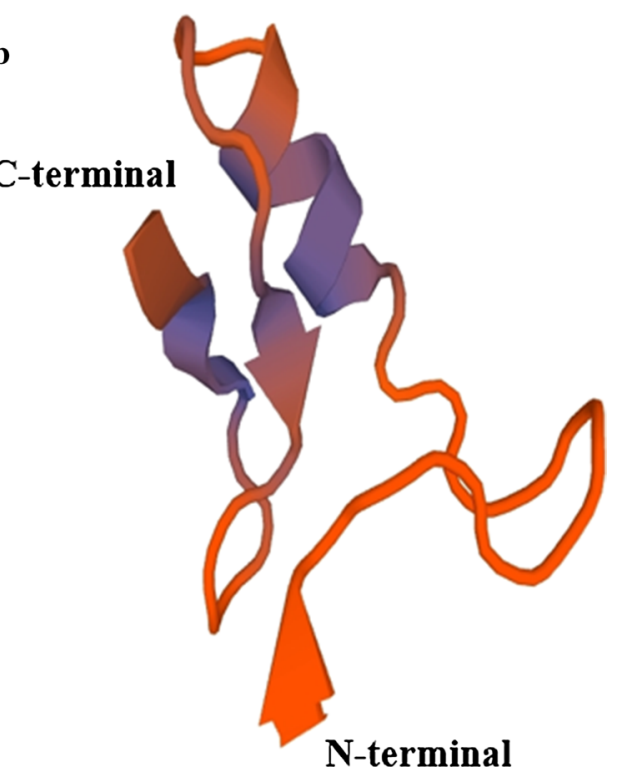

Fig. 1 Electrophoresis image of PCR (a) and predicted tertiary structure of protein encoded by BdPho (b)

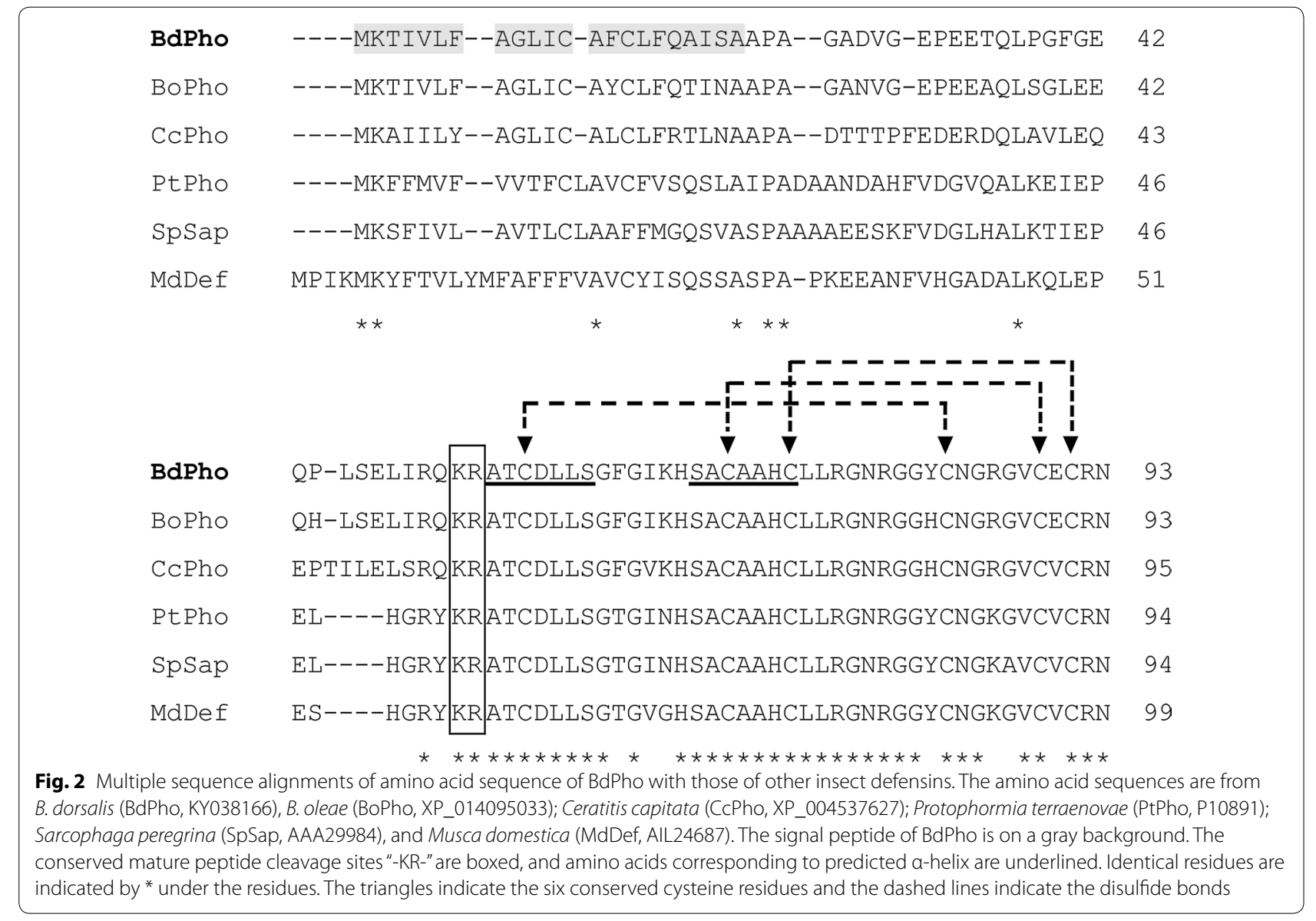




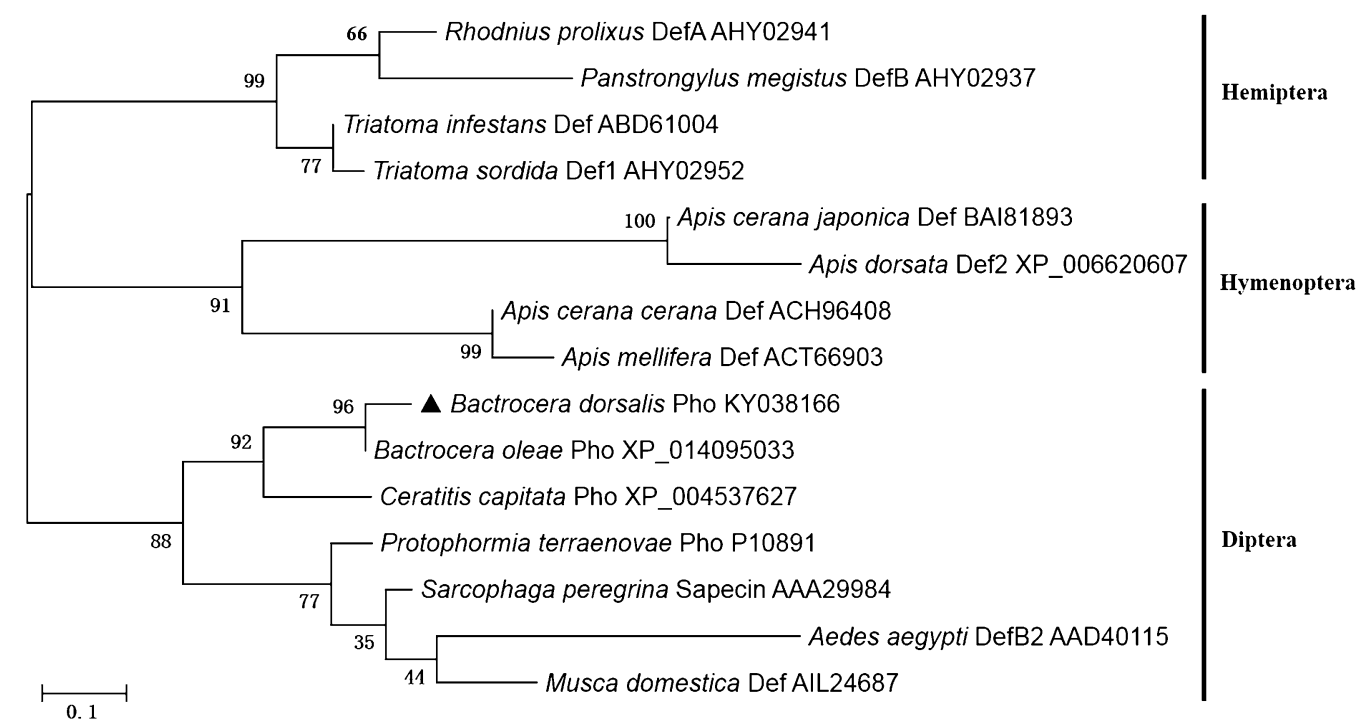

Fig. 3 Phylogenetic analysis of 15 insect phormicins and defensins. The phylogram of 15 insect defensin amino acid sequences was generated in MEGA 6.0 using Maximum Likelihood method. Scale bar $=0.1$ substitution/site. Bootstrapping analysis was performed 1000 replications. Accession numbers were labeled together with scientific name

occurred in adult and egg, respectively (Fig. 4a), besides, the mRNA level in adult stage was significantly higher than that in egg stage. As for adult body parts, the highest mRNA level of BdPho was found in the abdomen in both females and males, but the significant difference was only found between abdomen and head in females. The relative expression of BdPho in thorax and abdomen of female adult was significantly higher than that in male adult (Fig. 4b). For different tissues, the highest mRNA level of BdPho was observed in the fat body compared with those in Malpighian tubule and midgut, regardless of the sex (Fig. 4c).

\section{Transcriptional response of $B d P h o$ to immune challenge and mating}

As shown in Fig. 5a, the relative mRNA levels of BdPho significantly increased up to 7.46- and 14.53-fold at 3, and $6 \mathrm{~h}$ after PGN-EB injection compared to water injection, respectively. The expression of BdPho was also up-regulated at $9 \mathrm{~h}$ post PGN-EB injection, but without significant differences. The injection of PGN-SA did not show significantly induction of $B d P h o$ at 3,6 and 9 h post injection (Fig. 5a). The relative mRNA level of BdPho significantly increased up to 3.83 -fold at $12 \mathrm{~h}$ after starting mating compared to that of virgin females (Fig. 5b).
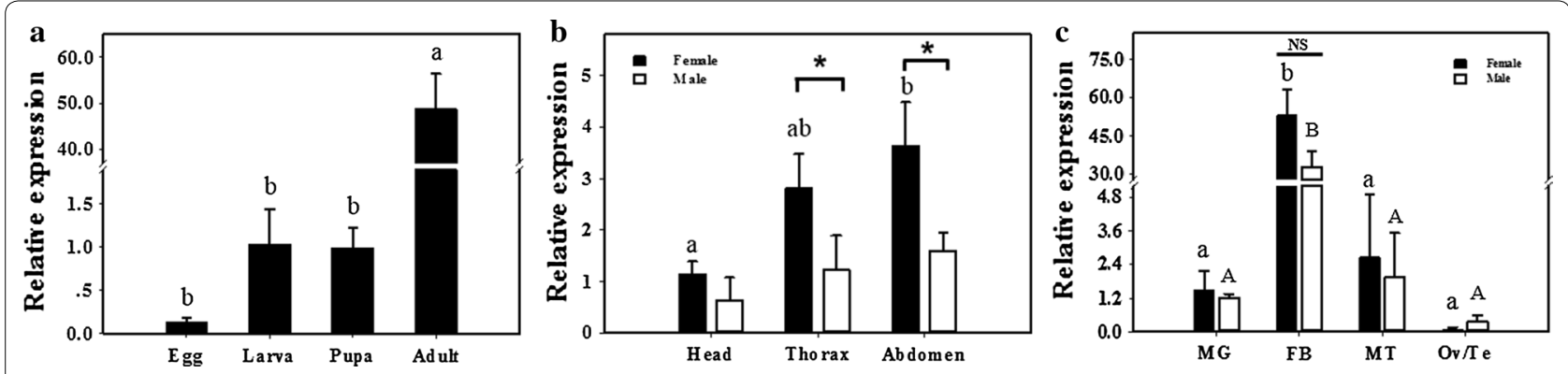

Fig. 4 The spatiotemporal expression profiles of $B d P h o$ in $B$. dorsalis. a The relative mRNA expression profiles of $B d P h o$ in egg, third instar larva, 5-day-old pupa and 5-day-old adult; b The relative mRNA expression profiles of BdPho in various body parts including head, thorax and abdomen; c The relative mRNA expression profiles of BdPho in different tissues including Malpighian tubule (MT), fat body (FB), mid gut (MG), ovary (Ov) and testis $(\mathrm{Te})$. Data are presented as mean $\pm \mathrm{SE}(n=4)$. Lowercase letters above black bars and uppercase letters above white bars indicate statistical difference by ANOVA followed by the Tukey's multiple comparison test $(P<0.05)$, respectively. Significant differences between female and male determined with $t$-test, asterisks indicate significant differences in relative expression $\left({ }^{*} P<0.05 ;{ }^{* *} P<0.01\right)$, and NS means no significant differences 

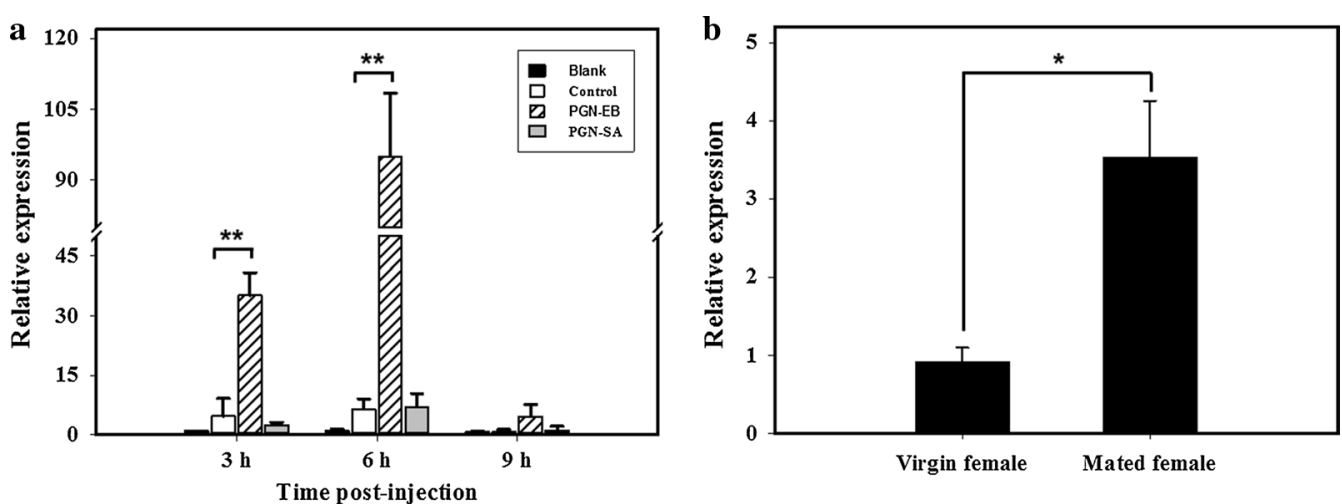

Fig. 5 Effects of PGN challenge and mating on the mRNA expression levels of BdPho in B. dorsalis. a Relative mRNA levels of BdPho after PGN-EB and PGN-SA challenge. Blank: without injection; Control: injected with $200 \mathrm{~nL}$ sterile endotoxin-free water; PGN-EB: injected with $200 \mathrm{~nL}$ PGN-EB solution; PGN-SA: injected with $200 \mathrm{~nL}$ PGN-SA solution. b Relative mRNA levels of BdPho after mating stimulation. Data represent mean relative level values (mean $\pm \mathrm{SE}$ ) to reference genes of three independent biological replicates. The two-tailed, unpaired $t$-test was used to test significance. Asterisks indicate significant differences in relative expression $\left({ }^{*} P<0.05 ;{ }^{*} P<0.01\right)$

\section{Discussion}

In the present study, we identified the cDNA sequence of a gene encoding phormicin in $B$. dorsalis. This phormicin belongs to the insects defensin family which are small cationic peptides and full of cysteines. Usually, defensins contain three peptide regions: signal peptide, prodefensin, and the mature peptide. As previously reported, the cleavage recognition sites between prodefensin and mature peptide were '-KR-' (Lowenberger et al. 1999). BdPho peptide also contained this conserved '-KR-' cleavage site. Multiple sequence alignments showed that BdPho has a high degree of identity (87.5-97.5\%) with other insect phormicins and defensins in mature peptides, particularly the six conserved cysteine residues, which form three disulfide bridges. These three disulfide bonds adopted a 'cysteine stabilized $\alpha \beta$ ' (CS $\alpha \beta)$ scaffold (Cornet et al. 1995), and the predicted tertiary structure also showed this conserved " $\alpha \beta$ " structure in BdPho (Fig. 1b). The predicted pairing patterns of these six conserved cysteine residues were the same as that of BdDef (C1-C4, C2-C5 and C3-C6) (Liu et al. 2017), and such strong conservation suggested that these cysteines and tertiary structures might have an important structural function in these proteins.

Previous studies demonstrated that the net positive charges carried by AMPs were associated with antimicrobial activities against diverse microbes (Wang et al. 2013b). Although different AMPs have different mechanisms and modes of action, the electrostatic attraction between the cationic AMPs and negatively charged microbial membranes was the first step of the interaction between AMPs and microbes (Yeung et al. 2011). In this study, we found that BdPho mature peptide possesses +2.9 charges at $\mathrm{pH} 7.0$ condition. Depending on these surplus positive charges, BdPho may easily react with negatively charged microbial membranes by electrostatic attraction.

Different insects can produce different AMPs, and the transcription levels of particular AMPs differ a lot among species of insect. Between different developmental stages, tagmata, and tissues of a specific insect, expression profiles of AMPs are variable. For instance, $B m D e f A$ is highly expressed in early pupa and adult stages of Bombyx mori (Wen et al. 2009). Similarly, a high level of constitutive expression of DmDef was found in pupa and adult stages of D. melanogaster (Dimarcq et al. 1994). However, in our previous study, BdDef was highly expressed in larva and adult stages of $B$. dorsalis (Liu et al. 2017). In contrast to $B d D e f, B d P h o$ was highly expressed in adult stage, but lowly expressed in egg, larva and pupa stages. Although $B d D e f$ and BdPho belong to the same defensin family, their different expression profiles probably suggest a different functional involvement in the immune system during the development of $B$. dorsalis. The results also indicated that $B d P h o$ might play important roles in fighting against invading microbes in the adult stage.

AMPs are expressed constitutively or induced by microorganisms infection (Lemaitre and Hoffmann 2007). Most insect AMP genes are mainly expressed in immune-related organs such as the fat body, midgut and haemolymph (Wang et al. 2006). Meanwhile, the induction of different insect AMPs, as well as induction in different tissues including fat body, reproductive tissues, midgut, and salivary gland in various insects have been reported (Liao et al. 2015; Tzou et al. 2002; Wang et al. 2013b). Furthermore, it has been well documented that the expression profiles of AMPs in different tissues are related to the category of AMP genes with variations 
across insect species. In $B$. mori, BmDefA was highly expressed in the hemocyte, silk gland and ovary, and lowly expressed in the fat body, Malpighian tubule and midgut (Wen et al. 2009). In contrast, BtDef was highly expressed in midgut and salivary, and expressed at a relatively lower level in the ovary and fat body in Bemisia tabaci (Wang et al. 2013b). In the current study, BdPho was expressed at a significantly high level in fat body, and at a much lower level in midgut, Malpighian tubule, testis and ovary. These results suggest that $B d P h o$ undertake its roles mainly in the fat body of adults to protect $B$. dorsalis from pathogens infection.

Though some AMPs failed to be induced in Drosophila (Hanson et al. 2016), injection of PGN has been considered as an effective way to investigate insect immune response (Neyen et al. 2014). The time course of transcription of BdPho was determined at 3-9 h after injection with two kinds of PGNs in female adult of $B$. dorsalis. The transcription level of BdPho was significantly induced at $3 \mathrm{~h}$ after PGN-EB challenge and reached a higher level at $6 \mathrm{~h}$ post injection; while injection of PGN-SA could not significantly stimulate the expression of $B d P h o$ from 3 to $9 \mathrm{~h}$ post injection. These findings implied that BdPho could be sharply induced by Gram-negative PGN but weakly induced by Grampositive PGN. The pattern of induction of $B d P h o$ is similar with that of BdDef in B. dorsalis (Liu et al. 2017) and Mdde in M. domestica (Wang et al. 2006). The BdDef was also strongly induced by PGN-EB at 3 and $6 \mathrm{~h}$, but the difference was that $B d D e f$ could be significantly induced by PGN-EB at $9 \mathrm{~h}$ and PGN-SA at $6 \mathrm{~h}$. Though BdPho and $B d D e f$ belong to the same family and have similar expression profiles in tagmata and tissues of $B$. dorsalis, the different induction patterns suggested that BdPho and $B d D e f$ possess different response intensity under the immune challenge of invaded bacteria. Similarly, the transcription of the Mdde was increased at $3 \mathrm{~h}$ post injection of bacteria, and the peak appeared at $36 \mathrm{~h}$ post challenge with Gram-negative bacterium (E. coli), while at the same time, injection of $S$. aureus (Gram-positive) did not induce expression of Mdde from 3 to $48 \mathrm{~h}$. On the other hand, some differences occurred between the induction of BdPho by PGN-EB and the induction of $M d d e$ by $E$. coli. For instance, infection of E. coli could strongly induce Mdde from 3 to $48 \mathrm{~h}$, and the peak appeared at 36-48 h post infection, whereas injection of PGN-EB could only strongly induced BdPho at 3 and $6 \mathrm{~h}$ post challenge, and the peak appeared at $6 \mathrm{~h}$ post injection. The differences might be due to injection of massive pure PGN-EB could induce BdPho quickly while injection of $E$. coli required the expansion of bacteria to induce $B d P h o$. It might also be due to different responses of innate immune system to E. coli (containing PGN and some other components) and PGN-EB.

Mating is considered as an indispensable physiological process in insects, and immunity is the basic aspect for individual survival. Thus, both immunity and mating are closely linked to fitness, and several studies reported the interactions between these two processes (Lawniczak et al. 2007). As previously reported, mating can have two different effect on immunity: either suppress or increase immunity. It was reported that there were tradeoffs between reproduction and immunity, and an increase in reproduction is generally coupled with a decrease in immunity (Fedorka et al. 2007). Mating leading to a reduction of immunity has been reported in Tenebrio molitor (Rolff and Siva-Jothy 2002), Atta colombica (Baer et al. 2006) and Matrona basilaris japonica (SivaJothy et al. 1998). However, some evidence suggested that immunity of insect might also increase after mating. For example, mating resulting in enhancement of immunity has been reported in Gryllus texensis (Shoemaker et al. 2006) and D. melanogaster (Domanitskaya et al. 2007; Peng et al. 2005). In this study, the results found that mating enhanced the immunity in $B$. dorsalis by upregulation of the AMP gene such as BdPho, which might protect the host from immune challenge during mating. This up-regulation of AMP gene may result from transfer of sperm and male accessory protein such as sex-peptide to the female during mating (Lawniczak and Begun 2004; Peng et al. 2005).

Taken all together, we cloned and characterized a phormicin gene from $B$. dorsalis, and investigated the spatiotemporal expression patterns of BdPho. Furthermore, we determined the mRNA levels of BdPho in female adults in response to peptidoglycan challenge and mating stimulation, which lays the foundation for understanding the molecular mechanisms in immune system and may help us to make use of insect pathogens for pest control. Furthermore, the basic knowledge derived from this study may provide information for extension the source of novel antibiotics.

\section{Additional files}

Additional file 1: Figure S1. Stability validation of RPS3 in this study. A, stability of RPS3 in different developmental stages and adult tagmata in B. dorsalis. E: eggs; L: larvae; P: pupae; A: adults; He: head; Th: thorax; Ab: abdomen. B, stability of RPS3 in different tissue of adult, mated female and virgin female. Mg: mid gut; FB: fat body; MT: Malpighian tubule; Ov: ovary; Te: testis; MF: mated female; VM: virgin female. C, stability of RPS3 after PGN challenge. EB: PGN-EB; SA: PGN-SA; W: sterile endotoxin-free water; CK: not injected.

Additional file 2: Figure S2. Distribution of $\mathrm{Cq}$ values of $a$-tublin and RPS3 obtained using qRT-PCR. 


\begin{abstract}
Abbreviations
AMP: antimicrobial peptide; Pho: phormicin; PGN: peptidoglycan; PGN-EB: peptidoglycans from Escherichia coli O111:B4; PGN-SA: peptidoglycans from Staphylococcus aureus; RH: relative humidity; RNA: ribonucleic acid; CDNA: complementary deoxyribonucleic acid; PCR: polymerase chain reaction; DNase: deoxyribonuclease; qRT-PCR: quantitative real-time PCR; ANOVA: analysis of variance; RT-PCR: reverse transcription PCR
\end{abstract}

\section{Authors' contributions}

SHL, HFL and YY carried out the experiments; SHL, DW, HBJ, WD, GRY and JJW wrote the paper; SHL, DW, HBJ, and JJW designed the research; JJW obtained funding. All authors read and approved the final manuscript.

\section{Author details}

1 Key Laboratory of Entomology and Pest Control Engineering, College of Plant Protection, Southwest University, Chongqing 400716, China. ${ }^{2}$ Academy of Agricultural Sciences, Southwest University, Chongqing 400716, China.

\section{Acknowledgements}

We thank Dr. Chongyu Liao and Dr. Yong Huang for useful suggestions in experimental design, and we thank Mr. Feng Shang for valuable suggestion to revision.

\section{Competing interests}

The authors declare that they have no competing interests.

\section{Availability of data and materials}

The datasets supporting the conclusions of this article are included within the article.

\section{Consent for publication}

This article does not contain any individual person's data.

\section{Ethics approval and consent to participate}

No human participants were involved in the study.

\section{Funding}

This research was supported in part by the earmarked fund for Modern Agroindustry (Citrus) Technology Research System of China (CARS-26).

\section{Publisher's Note}

Springer Nature remains neutral with regard to jurisdictional claims in published maps and institutional affiliations.

Received: 12 October 2017 Accepted: 29 December 2017

Published online: 11 January 2018

\section{References}

Baer B, Armitage SAO, Boomsma JJ (2006) Sperm storage induces an immunity cost in ants. Nature 441:872-875

Biasini M, Bienert S, Waterhouse A, Arnold K, Studer G, Schmidt T, Kiefer F, Cassarino TG, Bertoni M, Bordoli L, Schwede T (2014) SWISS-MODEL: modelling protein tertiary and quaternary structure using evolutionary information. Nucleic Acids Res 42:W252-W258

Buchon N, Broderick NA, Lemaitre B (2013) Gut homeostasis in a microbial world: insights from Drosophila melanogaster. Nat Rev Microbiol 11:615-626

Bulet P, Cociancich S, Reuland M, Sauber F, Bischoff R, Hegy G, Vandorsselaer A, Hetru C, Hoffmann JA (1992) A novel insect defensin mediates the inducible antibacterial activity in larvae of the dragonfly Aeschna cyanea (Paleoptera, Odonata). Eur J Biochem 209:977-984

Cheng DF, Guo ZJ, Riegler M, Xi ZY, Liang GW, Xu YJ (2017) Gut symbiont enhances insecticide resistance in a significant pest, the oriental fruit fly Bactrocera dorsalis (Hendel). Microbiome 5:13

Clarke AR, Armstrong KF, Carmichael AE, Milne JR, Raghu S, Roderick GK, Yeates DK (2005) Invasive phytophagous pests arising through a recent tropical evolutionary radiation: the Bactrocera dorsalis complex of fruit flies. Annu Rev Entomol 50:293-319

Combet C, Blanchet C, Geourjon C, Deléage G (2000) NPS@: network protein sequence analysis. Trends Biochem Sci 25:147-150

Cornet B, Bonmatin JM, Hetru C, Hoffmann JA, Ptak M, Vovelle F (1995) Refined three-dimensional solution structure of insect defensin $\mathrm{A}$. Structure 3:435-448

Dang XL, Tian JH, Yang WY, Wang WX, Ishibashi J, Asaoka A, Yi HY, Li YF, Cao Y, Yamakawa M, Wen SY (2009) Bactrocerin-1: a novel inducible antimicrobial peptide from pupae of oriental fruit fly Bactrocera dorsalis Hendel. Arch Insect Biochem Physiol 71:117-129

Dimarcq JL, Hoffmann D, Meister M, Bulet P, Lanot R, Reichhart JM, Hoffmann JA (1994) Characterization and transcriptional profiles of a Drosophila gene encoding an insect defensin. A study in insect immunity. Eur J Biochem 221:201-209

Domanitskaya EV, Liu HF, Chen SJ, Kubli E (2007) The hydroxyproline motif of male sex peptide elicits the innate immune response in Drosophila females. FEBS J 274:5659-5668

Fedorka KM, Linder JE, Winterhalter W, Promislow D (2007) Post-mating disparity between potential and realized immune response in Drosophila melanogaster. P Roy Soc B-Biol Sci 274:1211-1217

Hanson MA, Hamilton PT, Perlman SJ (2016) Immune genes and divergent antimicrobial peptides in flies of the subgenus Drosophila. BMC Evol Biol $16: 228$

Hellemans J, Mortier G, De Paepe A, Speleman F, Vandesompele J (2007) qBase relative quantification framework and software for management and automated analysis of real-time quantitative PCR data. Genome Biol 8:R19

Hoffmann JA (1995) Innate immunity of insects. Curr Opin Immunol 7:4-10

Hultmark D (1993) Immune reactions in Drosophila and other insects: a model for innate immunity. Trends Genet 9:178-183

Jiang XZ, Cong L, Niu JZ, Dou W, Wang JJ (2014) Alternative splicing contributes to the coordinated regulation of ferritin subunit levels in Bactrocera dorsalis (Hendel). Sci Rep 4:4806

Lambert J, Keppi E, Dimarcq JL, Wicker C, Reichhart JM, Dunbar B, Lepage P, Vandorsselaer A, Hoffmann J, Fothergill J, Hoffmann D (1989) Insect immunity: isolation from immune blood of the dipteran Phormia terranovae of two insect antibacterial peptides with sequence homology to rabbit lung macrophage bactericidal peptides. Proc Natl Acad Sci USA $86: 262-266$

Lamberty M, Ades S, Uttenweiler-Joseph S, Brookhart G, Bushey D, Hoffmann JA, Bulet P (1999) Insect immunity: isolation from the lepidopteran Heliothis virescens of a novel insect defensin with potent antifungal activity. J Biol Chem 274:9320-9326

Lamberty M, Zachary D, Lanot R, Bordereau C, Robert A, Hoffmann JA, Bulet $P(2001)$ Insect immunity: constitutive expression of a cysteine-rich antifungal and a linear antibacterial peptide in a termite insect. J Biol Chem 276:4085-4092

Lawniczak MKN, Begun DJ (2004) A genome-wide analysis of courting and mating responses in Drosophila melanogaster females. Genome 47:900-910

Lawniczak MKN, Barnes Al, Linklater JR, Boone JM, Wigby S, Chapman T (2007) Mating and immunity in invertebrates. Trends Ecol Evol 22:48-55

Lemaitre B, Hoffmann JA (2007) The host defense of Drosophila melanogaster. Annu Rev Immunol 25:697-743

Liao YY, Zuo YH, Tsai CL, Hsu CM, Chen ME (2015) cDNA cloning and transcriptional regulation of the cecropin and attacin from the oriental fruit fly, Bactrocera dorsalis (Diptera: Tephritidae). Arch Insect Biochem Physiol 89:111-126

Liu SH, Wei D, Yuan GR, Jiang HB, Dou W, Wang JJ (2017) Antimicrobial peptide gene cecropin-2 and defensin respond to peptidoglycan infection in the female adult of oriental fruit fly, Bactrocera dorsalis (Hendel). Comp Biochem Physiol B 206:1-7

Lowenberger CA, Smartt CT, Bulet P, Ferdig MT, Severson DW, Hoffmann JA, Christensen BM (1999) Insect immunity: molecular cloning, expression, and characterization of CDNAs and genomic DNA encoding three isoforms of insect defensin in Aedes aegypti. Insect Mol Biol 8:107-118

Matsuyama K, Natori S (1988) Molecular cloning of cDNA for sapecin and unique expression of the sapecin gene during the development of Sarcophaga peregrina. J Biol Chem 263:17117-17121

Neyen C, Bretscher AJ, Binggeli O, Lemaitre B (2014) Methods to study Drosophila immunity. Methods 68:116-128 
Peng J, Zipperlen P, Kubli E (2005) Drosophila sex-peptide stimulates female innate immune system after mating via the Toll and Imd pathways. Curr Biol 15:1690-1694

Petersen TN, Brunak S, von Heijne G, Nielsen H (2011) SignalP 4.0: discriminating signal peptides from transmembrane regions. Nat Methods 8:785-786

Rolff J, Siva-Jothy MT (2002) Copulation corrupts immunity: a mechanism for a cost of mating in insects. Proc Natl Acad Sci USA 99:9916-9918

Schmidt O, Theopold U, Strand M (2001) Innate immunity and its evasion and suppression by hymenopteran endoparasitoids. Bioessays 23:344-351

Shen GM, Wang XN, Dou W, Wang JJ (2012) Biochemical and molecular characterisation of acetylcholinesterase in four field populations of Bactrocera dorsalis (Hendel) (Diptera: Tephritidae). Pest Manag Sci 68:1553-1563

Shoemaker KL, Parsons NM, Adamo SA (2006) Mating enhances parasite resistance in the cricket Gryllus texensis. Anim Behav 71:371-380

Siva-Jothy MT, Tsubaki Y, Hooper RE (1998) Decreased immune response as a proximate cost of copulation and oviposition in a damselfly. Physiol Entomol 23:274-277

Tamura K, Peterson D, Peterson N, Stecher G, Nei M, Kumar S (2011) MEGA5: molecular evolutionary genetics analysis using maximum likelihood, evolutionary distance, and maximum parsimony methods. Mol Biol Evol 28:2731-2739

Tian CH, Gao B, Fang Q, Ye GY, Zhu SY (2010) Antimicrobial peptide-like genes in Nasonia vitripennis: a genomic perspective. BMC Genomics 11:187

Tzou P, Reichhart JM, Lemaitre B (2002) Constitutive expression of a single antimicrobial peptide can restore wild-type resistance to infection in immunodeficient Drosophila mutants. Proc Natl Acad Sci USA 99:2152-2157
Ueda K, Imamura M, Saito A, Sato R (2005) Purification and cDNA cloning of an insect defensin from larvae of the longicorn beetle, Acalolepta luxuriosa. Appl Entomol Zool 40:335-345

Unckless RL, Howick VM, Lazzaro BP (2016) Convergent balancing selection on an antimicrobial peptide in Drosophila. Curr Biol 26:257-262

Wang JX, Zhao XF, Liang YL, Li L, Zhang W, Ren Q, Wang LC, Wang LY (2006) Molecular characterization and expression of the antimicrobial peptide defensin from the housefly (Musca domestica). Cell Mol Life Sci 63:3072-3082

Wang JJ, Wei D, Dou W, Hu F, Liu WF, Wang JJ (2013a) Toxicities and synergistic effects of several insecticides against the oriental fruit fly (Diptera: Tephritidae). J Econ Entomol 106:970-978

Wang ZZ, Shi M, Ye XQ, Chen MY, Chen XX (2013b) Identification, characterization and expression of a defensin-like antifungal peptide from the whitefly Bemisia tabaci (Gennadius) (Hemiptera: Aleyrodidae). Insect Mol Biol 22:297-305

Wen HX, Lan XQ, Cheng TC, He NJ, Shiomi K, Kajiura Z, Zhou ZY, Xia QY, Xiang ZH, Nakagaki M (2009) Sequence structure and expression pattern of a novel anionic defensin-like gene from silkworm (Bombyx mori). Mol Biol Rep 36:711-716

Yeung ATY, Gellatly SL, Hancock REW (2011) Multifunctional cationic host defence peptides and their clinical applications. Cell Mol Life Sci 68:2161-2176

Yi HY, Chowdhury M, Huang YD, Yu XQ (2014) Insect antimicrobial peptides and their applications. Appl Microbiol Biotechnol 98:5807-5822

\section{Submit your manuscript to a SpringerOpen ${ }^{\circ}$ journal and benefit from:}

- Convenient online submission

$\checkmark$ Rigorous peer review

- Open access: articles freely available online

- High visibility within the field

- Retaining the copyright to your article

Submit your next manuscript at $\boldsymbol{\nabla}$ springeropen.com 